\title{
Benchmarking performance in organ donation programs: dependence on demographics and mortality rates
}

\author{
[La performance comparative des programmes de don d'organes en fonction des \\ données démographiques et des taux de mortalité] \\ Lianne Barnieh MSc, $†$ David Baxter, $\$$ Paul Boiteau MD, $\ddagger$ Braden Manns MD MSc, ${ }^{*} \dagger$ \\ Christopher Doig MD MSc*$† \ddagger$
}

Purpose: Donors whose diagnosis of death is based upon neurologic criteria are the primary source of organs for human transplantation. The current measure of effectiveness of organ donation programs is the crude statistic, donors per million population (DPMP). This statistic represents the number of available donors, divided by the potential donor population. Comparisons between transplantation programs are done using the DPMP statistic. We sought to determine if variance in organ donation rates, reported as DPMP could be accounted for by differences in population demographics, specifically age and gender-specific mortality rates.

Methods: We obtained the population distribution and deaths for the year 2000 for the Calgary Health Region (CHR) and the country of Spain. Expected deaths were then calculated by standardizing the sample, based upon weighted averages of age, gender and cause-specific mortality rates.

Results: In 2000, Spain reported a crude organ donation rate of 33.9 DPMP. Standardizing the observed deaths in Spain using the CHR population distribution and calculating expected deaths based on the $\mathrm{CHR}$ rates, resulted in an adjusted rate of 19.2 DPMP $(P<0.05)$.

Conclusions: These results bring into question the reliability of using crude DPMP as a measure of organ and tissue donation program performance. Alternative measures of benchmarking performance in organ donation programs should be considered.
Objectif: Les donneurs dont la mort est diagnostiquée selon des critères neurologiques sont la principale source d'organes pour la transplantation chez les humains. La mesure courante de l'efficacité des programmes de dons d'organes est la statistique brute, les donneurs par million de population (DPMP). Cette statistique représente le nombre de donneurs existants divisé par la population de donneurs potentiels. Les comparaisons entre les programmes de don utilisent la statistique des DPMP. Nous voulions déterminer si la variance des taux de dons d'organes, présentée comme les DPMP, peut s'expliquer par les différences démographiques des populations, spécialement les taux de mortalité spécifiques à l'âge et au sexe.

Méthode: Nous avons obtenu la distribution de la population et les décès pour l'an 2000 dans la région sanitaire de Calgary (RSC) et en Espagne. L'estimation des décès a été calculée par l'uniformisation de l'échantillon fondée sur les moyennes pondérées des taux de mortalité moyens spécifiques à l'âge, au sexe et à la cause du décès.

Résultats: En 2000, l'Espagne a rapporté un taux brut de don d'organes de 33,9 DPMP. L'uniformisation des décès observés en Espagne selon la distribution de la population de la RSC et le calcul des décès attendus selon les taux de la RSC ont fourni un taux ajusté de 19,2 DPMP $(P<0,05)$.

Conclusion: Ces résultats remettent en question la fiabilité de l'usage des DPMP bruts comme mesure de la performance du programme de don d'organes et de tissu. Des mesures différentes de la performance comparative des programmes de don d'organes doivent être envisagées.

From the Departments of Medicine, ${ }^{*}$ Community Health Sciences; $†$ and Critical Care Medicine, $\ddagger$ Faculty of Medicine, The University of Calgary, Calgary, Alberta; and the Urban Futures Institute, $\$$ Vancouver, British Columbia, Canada.

Address correspondence to: Dr. Christopher James Doig, Rm EG23G, Foothills Medical Centre, 1403-29th Street NW, Calgary, Alberta

T2N 2T9, Canada. Phone: 403-944-1691; Fax: 403-283-9994; E-mail: cdoig@ucalgary.ca

Accepted for publication August 23, 2005.

Revision accepted December 15, 2005.

Final revision accepted January 17, 2006.

The authors declare no financial conflict of interest. The Urban Futures Institute is a non-profit membership society that carries out research to provide public information on changes affecting population, community and land use. 
$\mathrm{T}$ HE majority of organs procured from cadaveric donors are from individuals determined dead by neurologic criteria (brain-stem death). ${ }^{1}$ Two causes of death, transport/ motor vehicle accidents (MVAs) and deaths from cerebrovascular disease, represent the majority of patients whose diagnosis of death is based upon neurologic criteria, and from whom organs can potentially be procured. Organ donation is managed by regional or national programs, and the effectiveness of these programs is often measured according to the number of donors per million population (DPMP); simply, the number of donors divided by the potential donor population. However, DPMP is a crude estimate of the rate of organ donation, and makes three assumptions: 1 ) that age and gender distribution is similar for all populations; 2 ) that age and gender-adjusted death rates from traumatic or cerebrovascular brain injury are similar for all populations; and 3) that all programs use the same definition of organ donor. ${ }^{1}$ These assumptions have important limitations.

In 1989, Spain introduced a process of quality improvement in the identification and processing of organ donors. The Organización Nacional de Transplantes has been responsible for increasing organ donation rates in Spain. The Spanish DPMP of 33.6 is one of the highest in the world, and is now considered a benchmark for other programs..$^{2,3}$ Inferentially, it has been suggested that organ donation programs with DPMPs substantially below $\mathbf{3 3 . 6}$ may be failing patients awaiting a transplant.

Due to concerns of the validity of the crude metric of DPMP in comparing transplant programs, we undertook a study to determine whether the variance in published DPMP rates in different jurisdictions may be influenced by differences in population demographics. Specifically, we sought to compare DPMP data from Spain, with a documented high DPMP, to that of a major urban centre in Canada.

\section{Methods}

The DPMP data for the Calgary Health Region (CHR) were obtained for the year 2000 from the CHR health systems and analysis unit. The CHR administers medical and surgical services to the residents of the cities of Calgary and Airdrie, and 20 nearby small towns in Southern Alberta (total population 930,000). The study population was defined as individuals with a postal code in the CHR geographic domain. Deaths were classified by the International Classification of Diseases, 10th Revision. ${ }^{4}$ All deaths in categories I60-I69 (cerebrovascular disease) and V00-V99 (transport accidents) were determined.

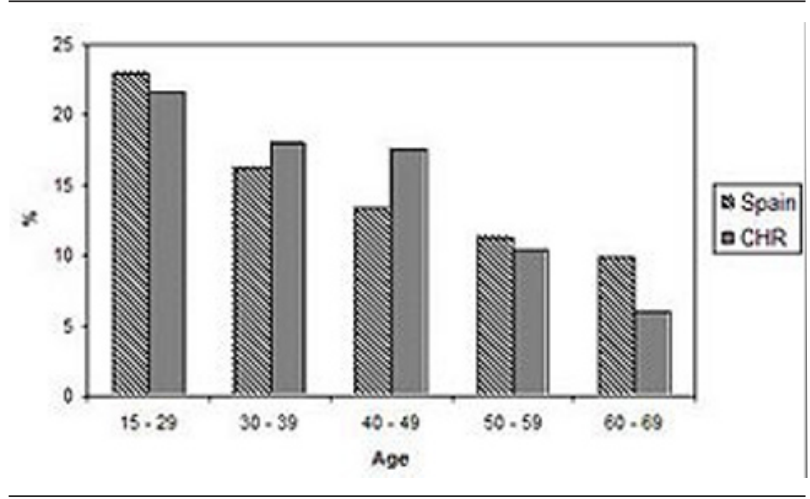

FIGURE 1 Population distribution shown in percentage. CHR = Calgary Health Region .

Deaths in Spain for the calendar year 2000 were obtained from the website of the Instituto Nacional de Estadistica (www.ine.es). Causes of death attributed to enfermedades cerebrovasculares (cerebrovascular disease), and accidentes de traffico de vehiculos de motor (MVAs) were included. ${ }^{5}$ The population in Spain in 2000 was $39,927,392$. The two causes of death (transport/MVAs and deaths from cerebrovascular diseases) were selected for this analysis, since cumulatively, they represent the majority of patients from whom organs can potentially be procured. Given that organ donors are generally not accepted above the age of 69 , this analysis was restricted to data from donors between 15 to $69 \mathrm{yr}$ of age.

To test the dependency of DPMP on population distribution, as well as age and gender-specific mortality rates, direct standardization was used. ${ }^{6}$ For example, to standardize the CHR population, proportions of the total population were calculated for each age and gender group in Spain. This proportion was then multiplied by the total population of the CHR, from which the standardized population of the CHR was determined. The reverse was done for Spain. To calculate the expected deaths in the CHR, the mortality rate in Spain for each cause, age and gender group was multiplied by the new standard population for the CHR. Again, the reverse was done for Spain. The adjusted DPMP was then calculated based upon the percent difference between observed and expected deaths, and the proportional distribution of brain death by etiology.

Data were compared using Fisher's exact test. Statistical significance was assumed when $P<0.05$. 
TABLE I Observed and standardized populations, CHR and Spain, 2000

\begin{tabular}{|c|c|c|c|c|c|}
\hline Ages & $15-29$ & $30-39$ & $40-49$ & $50-59$ & $60-69$ \\
\hline \multicolumn{6}{|c|}{ CHR observed population } \\
\hline Female & 100,534 & 84,281 & 80,671 & 48,214 & 29,004 \\
\hline Male & 101,827 & 83,795 & 83,357 & 49,496 & 27,463 \\
\hline \multicolumn{6}{|c|}{ CHR standardized population } \\
\hline Female & 104,868 & 74,740 & 62,691 & 53,420 & 49,447 \\
\hline Male & 109,556 & 76,402 & 62,290 & 51,395 & 43,629 \\
\hline \multicolumn{6}{|c|}{ Spain observed population } \\
\hline Female & $4,472,442$ & $3,187,524$ & $2,673,668$ & $2,278,279$ & $2,108,843$ \\
\hline Male & $4,672,339$ & $3,258,482$ & $2,656,567$ & $2,191,905$ & $1,860,684$ \\
\hline \multicolumn{6}{|c|}{ Spain standardized population } \\
\hline Female & $4,287,587$ & $3,594,427$ & $3,440,467$ & $2,056,237$ & $1,236,966$ \\
\hline Male & $4,342,731$ & $3,573,700$ & $3,555,020$ & $2,110,912$ & $1,171,246$ \\
\hline
\end{tabular}

$\overline{\mathrm{CHR}}=$ Calgary Health Region.

TABLE II Observed and expected deaths, CHR and Spain, 2000

\begin{tabular}{|c|c|c|c|c|c|}
\hline Ages & $15-29$ & $30-39$ & $40-49$ & $50-59$ & $60-69$ \\
\hline \multicolumn{6}{|c|}{ CHR observed deaths } \\
\hline Female CVA & 0 & 0 & 5 & 3 & 11 \\
\hline Female MVA & 8 & 1 & 3 & 2 & 0 \\
\hline Male CVA & 0 & 1 & 8 & 9 & 10 \\
\hline Male MVA & 15 & 8 & 9 & 8 & 2 \\
\hline \multicolumn{6}{|c|}{ CHR expected deaths* } \\
\hline Female CVA & 0.68 & 2.02 & 2.56 & 7.22 & 23.94 \\
\hline Female MVA & 9.80 & 3.92 & 1.87 & 3.47 & 3.99 \\
\hline Male CVA & 1.01 & 2.27 & 5.96 & 14.77 & 41.08 \\
\hline Male MVA & 39.91 & 20.02 & 15.31 & 12.64 & 11.35 \\
\hline \multicolumn{6}{|c|}{ Spain observed deaths } \\
\hline Female CVA & 29 & 86 & 164 & 308 & 1021 \\
\hline Female MVA & 418 & 167 & 157 & 148 & 170 \\
\hline Male CVA & 43 & 97 & 254 & 630 & 1752 \\
\hline Male MVA & 1,702 & 854 & 653 & 539 & 484 \\
\hline \multicolumn{6}{|c|}{ Spain expected deathst } \\
\hline Female CVA & 0 & 0 & 213.24 & 127.94 & 469.13 \\
\hline Female MVA & 314.19 & 42.65 & 127.94 & 85.30 & 0.0 \\
\hline Male CVA & 0 & 42.65 & 341.19 & 383.83 & 426.48 \\
\hline Male MVA & 639.72 & 341.19 & 383.83 & 341.19 & 85.30 \\
\hline
\end{tabular}

CHR = Calgary Health Region; $\mathrm{CVA}=$ deaths of cerebrovascular origin; $\mathrm{MVA}=$ motor vehicle accidents. ${ }^{*} \mathrm{CHR}$ observed deaths standardized to Spanish population and age and gender specific mortality rates to produce expected deaths. $†$ Spain observed deaths standardized to CHR population and age and gender specific mortality rates to produce expected deaths.

\section{Results}

The population distributions according to age were similar when comparing CHR to Spain for the year 2000 (Figure 1). The observed and standardized population distribution in Spain and the CHR (restricted to ages 15-69), stratified by age and gender, is presented in Table I. The number of observed and expected deaths from MVAs and cerebrovascular causes, stratified by gender, is presented in Table II. There were 5,292 deaths from MVAs and 4,383 cerebrovascular deaths in the year 2000 in Spain. Once standardized according to age, gender and cause-specific mortality rates observed in the CHR, the expected deaths in Spain decreased by $55 \%$ for MVAs and by $54 \%$ for deaths of cerebrovascular origin (Figure 2). In 2000, the reported crude DPMP in Spain was 33.9. In Spain, $26.1 \%$ and $55 \%$ of brain deaths were due to MVAs and deaths of cerebrovascular origin, respectively. Therefore, correcting for the decrease in expected deaths (from the standardization procedure), Spain's adjusted DPMP would decrease to 19.7 , which is significantly different from the crude DPMP of 33.9 (Fisher's exact test, $P=0.03$ ).

The reverse analysis also held true. If the CHR had the age and gender cause-specific mortality rates observed in Spain, the expected deaths in the CHR 


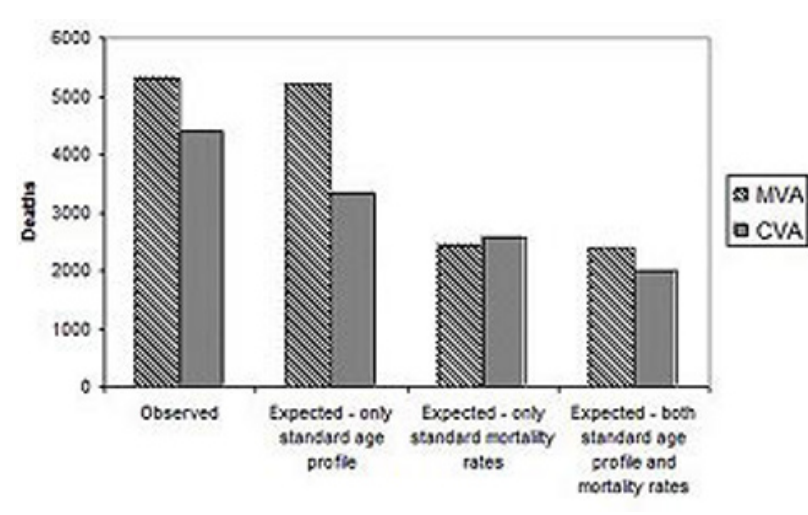

FIGURE 2 Observed and expected mortality rates (standardized by age and gender), Spain, 2000. CVA = deaths of cerebrovascular origin; $\mathrm{MVA}=$ motor vehicle accident .

would have increased $218 \%$ and $284 \%$, for deaths due to MVAs and cerebrovascular origin, respectively. To adjust the DPMP, the same method as above was applied. In the CHR, $33 \%$ and $42 \%$ of brain deaths were due to MVAs and cerebrovascular causes. Therefore, correcting proportionately for the increase in deaths, the adjusted DPMP in the CHR for the year 2000 was 32.8. This value is significantly greater than the crude DPMP of 17.4 (Fisher's exact test, $P=0.03$ ).

\section{Discussion}

A twofold difference in crude DPMP rates existed in the year 2000 between the CHR and Spain. However, our analysis demonstrates that at least some variance in the crude DPMPs can be explained by differences in the mortality rates from the major causes of brain death: traumatic brain injury from MVAs and cerebrovascular accidents.

Geographical differences in the incidence of potential organ donors have been recognized from other jurisdictions. ${ }^{1}$ As shown with our analysis, differences in deaths due to MVAs can account for a portion of the DPMP. Deaths from MVAs per million population in Spain in 1998 exceeded those of Canada by one third. ${ }^{7}$ These differences may have been due to multiple factors including variable adoption of public health preventative practices (mandatory use of seatbelts, reduction of speed limits) that affect the incidence of MVAs. ${ }^{7}$

Discrepancies in definitions may also account for observed differences between published crude DPMPs. For example, Spain defines a cadaveric donor as "one from whom at least one vascularized solid organ was recovered for the purpose of transplantation". 8 Therefore, in those instances where an organ was recovered but not transplanted, the patient was still defined as a donor. In contrast, the definition in Canada is "a solid organ donor is one where at least one solid organ has been used for transplant". ${ }^{9}$ If a condition renders a potential donor or a recovered organ unsuitable and no transplantation occurs, that patient cannot be counted as a donor, even though an organ was recovered. Unlike underlying demographic patterns of a population, data reflecting these differences were not available, and therefore adjusting the crude DPMPs for these discrepancies was not possible.

Our results demonstrate that crude DPMP is an imperfect measure of organ donation program performance. Although it is a commonly-used benchmark, it may not truly reflect the effectiveness of a program from one region or country to another, nor the reality of the donation demographics. ${ }^{10}$ The National Coordinating Committee for Organ and Tissue Donation set a target goal for Canada of a crude cadaveric donor rate of 25 DPMP. ${ }^{11}$ If the death rates observed in the CHR are consistent across Canada, this rate may not be feasible. Moreover, as demonstrated herein, crude DPMP may not be the appropriate performance measure. The effectiveness of organ donation programs should be based upon standardized key performance indicators. Key performance indicators, which are usually expressed as proportions, have been previously described and include: the identification of brain death, the approach to families for consent and consent success, and the number of organs retrieved and transplanted. ${ }^{12}$ For example, in the $\mathrm{CHR}$, the average consent rate over the years 2000 to 2002 was $81.6 \%$ compared to $78.2 \%$ in Spain. During the same time period, there was one more organ transplanted per donor in the CHR (3.5 organs per donor) than in Spain (2.5 organs per donor). Unfortunately, the reporting of many of these variables has not been required of health systems, or as part of vital statistics.

The Organización Nacional de Transplantes program in Spain is a fine example of a national program to enhance organ donation rates, and has forced the health system to report and be accountable for the organ donation process. However, our data suggest that comparisons in performance based on crude DPMP may not fairly reflect the variance in the incidence of brain death, and the effectiveness of organ donation programs. We suggest that other key performance indicators, as described above, be used. 


\section{References}

1 Hauptman P, O'Connor K. Procurement and allocation of solid organs for transplantation. N Engl J Med 1997; 336: 422-31.

2 Matesanz R. Organ donation for transplantation: "The Spanish Model”. Madrid: Grupo Aula Medica; 1995.

3 Ferriman A. Spain tops the table for organ donation. BMJ 2000; 321: 1098.

4 World Health Organisation. International Classification of Diseases - 10th revision. Geneva: WHO; 1994.

5 Instituto Nacional de Estadistica (homepage on the Internet). Available from URL; www.ine.es, , c2003 (cited 2003 July 27).

6 Last JM. A Dictionary of Epidemiology. New York: Oxford University Press; 2001.

7 Baxter D. Beyond comparison: Canada's organ donation rates in an international context. Vancouver: The Urban Futures Institute Report 51; 2001.

8 Tuppin P, Noury D, Houssin D. United Kingdom: for an international cadaver organ donor definition. Transplantation 2003; 76: 273.

9 Canadian Organ Replacement Register. CORR Annual Reports. Ottawa: Canadian Institute for Health Information; 2002.

10 Luskin R, Delmonico F. Assessing organ donation from the dead should not be done by reporting a census of the living. Am J Transplant 2003; 3: 1185-7.

11 Health Canada. A coordinated and comprehensive donation and transplantation strategy for Canada. Ottawa: National Coordinating Committee on Organ and Tissue Donation and Transplantation; 1999.

12 Goodman C, Karweit J, Savage K, Gubens M. Increasing organ donation and transplantation: the challenge of evaluation. Washington, DC: Department of Health and Human Services; 1998: Contract: HHS100-97-0012. 